\title{
MULTIPLE CONGENITAL CARDIOVASCULAR DEFECTS INCLUDING TYPE IV PERSISTENT TRUNCUS ARTERIOSUS IN A SHETLAND PONY - SHORT COMMUNICATION
}

\author{
Marian TAULESCU ${ }^{1 *}$, Chiara PALMIERI ${ }^{2}$, Joshua LeACH$^{3}$, Andras NAGY ${ }^{1}$, Ciprian OBer $^{4}$, \\ Mihai CERNEA ${ }^{5}$ and Cornel $\mathrm{CATOI}^{1}$ \\ ${ }^{1}$ Pathology Department, Faculty of Veterinary Medicine, 3-5 Calea Mãnãştur, 400372 \\ Cluj-Napoca, Romania; ${ }^{2}$ School of Veterinary Science, The University of Queensland, \\ Gatton, Queensland, Australia; ${ }^{3}$ School of Veterinary Medicine, University of Glasgow, \\ Glasgow, United Kingdom; ${ }^{4}$ Department of Anaesthesiology and Surgery and \\ ${ }^{5}$ Department of Pharmacology, Faculty of Veterinary Medicine, Cluj-Napoca, Romania
}

(Received 24 August 2015; accepted 4 May 2016)

This case report describes the pathological findings of multiple congenital cardiac defects in a 2-year-old female Shetland pony with clinical signs of chronic respiratory distress. Persistent truncus arteriosus (PTA) type IV, interventricular septal defect, overriding aorta, pulmonary trunk agenesis, pulmonary arteries arising from the descending aorta, and compensatory right ventricular hypertrophy were observed.

Key words: Congenital anomaly, heart defects, persistent truncus arteriosus, pony

Congenital heart defects are common in humans, dogs and horses (Thomas, 2006). In horses, ventricular septal defects (VSD) (Binanti et al., 2014) and patent ductus arteriosus (PDA) (Steyn et al., 1989) are the most common.

Other congenital malformations of the great vessels, such as complete transposition (Sleeper and Palmer, 2005), persistent right aortic arch (Van der Linde-Sipman et al., 1979) and aortic origin of the right pulmonary artery (Reimer et al., 1993) have been reported occasionally.

Multiple congenital defects of both the heart and the large vessels (complex congenital heart disease) have been described in horses (Vitums and Bayly, 1982) and in one pony (Critchley, 1976). Finally, a right pulmonary artery originating from the aorta has been reported in a pony (Reimer et al., 1993).

Persistent truncus arteriosus (PTA) (truncus arteriosus communis) in domestic animals is a relatively rare congenital malformation accounting for about $3 \%$ of all congenital heart defects. PTA is characterised by a single great artery arising from the heart and providing systemic, pulmonary and coronary circula-

*Corresponding author; E-mail: taulescumarian@yahoo.com; Phone: 0040 (0) 2645-96384/ 172 
tion (Steyn et al., 1989). PTA has been described in horses (Steyn et al., 1989) and dogs (Serres et al., 2009).

\section{Materials and methods}

\section{Case description}

A 2-year-old female Shetland pony with a clinical history of anorexia, intermittent colic, absent defecation, and chronic respiratory distress (cyanosis, shortness of breath, tachypnoea, dyspnoea, coughing on exertion) culminating in death was referred to the Pathology Department of the Faculty of Veterinary Medicine of Cluj-Napoca (Romania) for a complete postmortem investigation.

\section{Results}

Necropsy revealed chronic, bilateral and severe pulmonary congestion and oedema, and a small amount $(50 \mathrm{ml})$ of clear fluid in the pleural space. The heart was globoid in shape, although maintaining a normal topography within the thorax. A careful examination of the heart and associated major blood vessels revealed multiple severe congenital defects. A large orifice $(15 \mathrm{~mm} \times 14 \mathrm{~mm})$ was present in the upper, membranous portion of the interventricular septum, immediately below the aortic valve (Fig. 1A). The aorta was positioned directly over the ventricular septal defect, instead of over the left ventricle (Fig. 1B). Gross examination of the right side of the heart revealed absence of both the pulmonic valve and the pulmonary trunk opening. The right ventricle instead is shown to communicate with the aorta via the ventricular septal defect and the pulmonary arteries were found to arise from the descending aorta. According to the classification system proposed by Collette and Edwards (1949), this vascular malformation is classified as a Persistent Truncus Arteriosus (PTA) type 4. The right ventricular wall was thicker (about $18 \mathrm{~mm}$ ) than normal with a left ventricle/right ventricle $(\mathrm{LV} / \mathrm{RV})$ ratio of $1: 1$ due to myocardial compensatory hypertrophy (Fig. 1C). Histopathology of the right ventricular myocardium showed diffuse enlargement of the cardiomyocytes and multifocal mild increased intercellular stroma (Fig. 1D). The right atrium was severely enlarged, while the other large blood vessels, including the pulmonary veins and the cranial and caudal vena cava were normal.

Grossly, within the abdominal cavity there was severe, chronic, diffuse, fibrinous peritonitis with multiple fibrous adhesions between the small and large intestine and the parietal peritoneum. A small $(0.5 \mathrm{~cm}$ in diameter) focal perforated ulcer covered by multiple fibrous adhesions was observed in the distal caecum. A small amount of intestinal content was seen floating in the peritoneal cavity. 


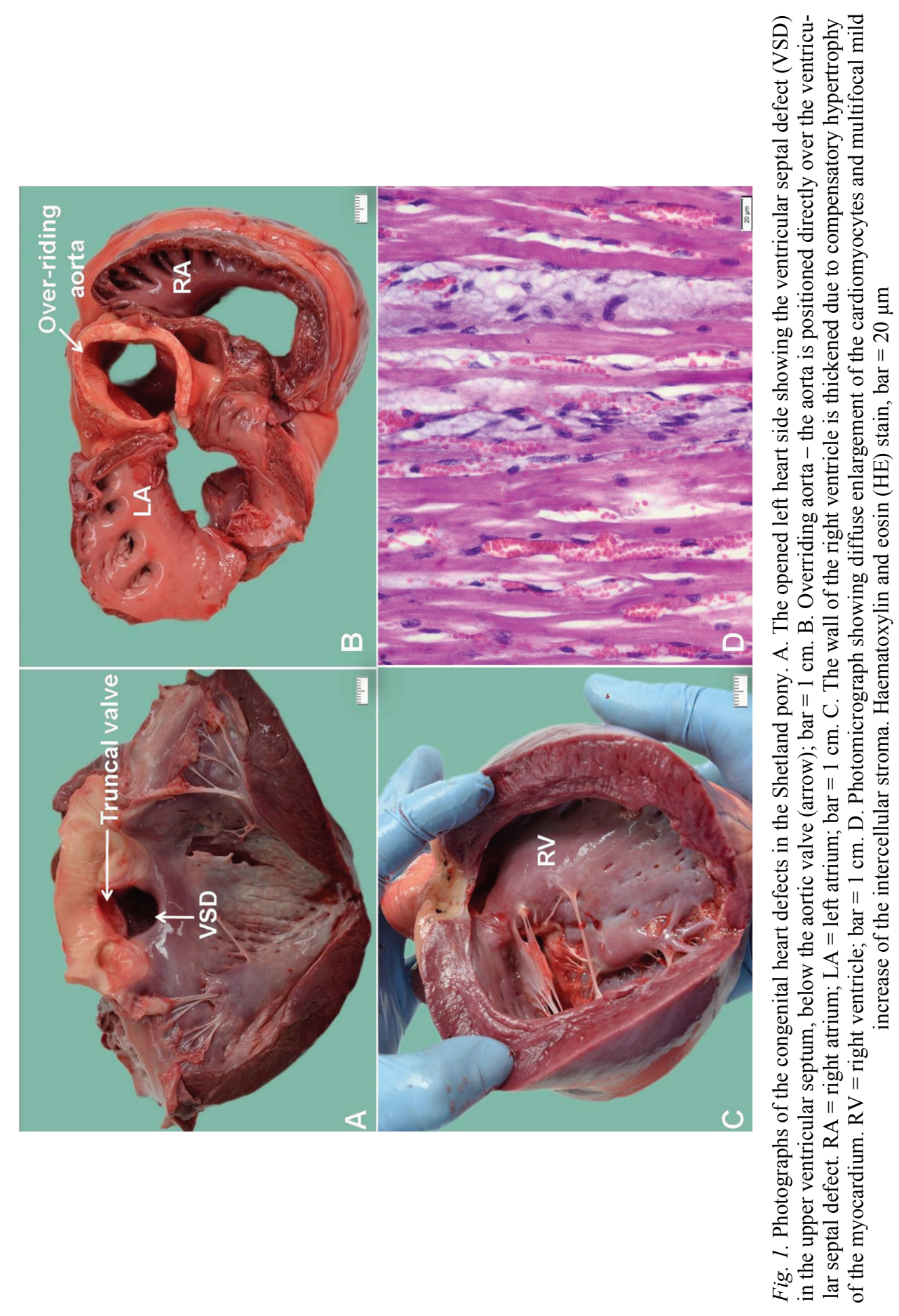


A final diagnosis of persistent truncus arteriosus (PTA) type IV, interventricular septal defect, overriding aorta, right ventricular hypertrophy, pulmonary trunk agenesis and abnormal origin of the pulmonary arteries from the descending aorta was made.

\section{Discussion}

According to Collette and Edwards (1949), there are four types of PTA: in type I, which is the most common, the pulmonary trunk arises from the truncus and then divides into the right and left pulmonary arteries (PAs); in type II, the right and left PAs originate adjacent to one another from the medial wall of the truncus; in type III, the right and left PAs arise from more widely separated orifices on the medial truncal wall; in type IV (pseudotruncus), true branch PAs are absent and pulmonary blood flow is derived from aortico-pulmonary collaterals.

In our case, a PTA type IV, characterised by absent pulmonary trunk and pulmonary arteries arising from the descending aorta, was diagnosed.

A single large artery limited by a bicuspid valve and overriding both ventricles was observed with two distinct pulmonary arteries arising from the common arterial trunk. A large interventricular septal defect was associated with a low-velocity bidirectional shunt (Serres et al., 2009).

Animals affected by severe congenital defects are unable to survive in utero, while those with mild lesions may be asymptomatic during their entire life or occasionally referred for gradually developing signs of cardiac failure, poor exercise tolerance and cyanosis (Miller et al., 2012). The most common clinical signs of heart disease in adult horses include loss of condition, increased fatigue during exertion, shortness of breath, tachypnoea or dyspnoea, weakness, occasional collapse or fainting, and fluid accumulation in the abdominal cavity or beneath the skin of the lower thorax. Depending on the severity of the condition, these signs may occur only during moderate or strenuous exercise (Thomas, 2006). In our case, the animal developed anorexia, chronic respiratory distress and exercise intolerance; however, a cardiovascular problem was not suspected.

The clinical signs observed in this animal were mostly secondary to pulmonary trunk atresia resulting in the inability of the cardiopulmonary system to supply adequate oxygenated blood to meet the demand. The right ventricular hypertrophy may be considered a secondary adaptation caused by the increased right-sided venous return and increased right ventricular preload (Vitums and Bayly, 1982).

The chronic peritonitis, most likely secondary to the focal caecal perforation and the progressive accumulation of fluid induced by the cardiac failure, explained the intermittent colic syndrome observed in our case.

Although in many species congenital anomalies have been associated with different causes, including the exposure of pregnant dams to various chemicals 
and drugs, physical agents, toxins or nutritional deficiencies (Miller et al., 2012), in the present case the pathogenesis is unknown and a genetic basis may be suspected.

To the authors' knowledge, this is the first case of persistent truncus arteriosus type IV in a pony, and although the pathogenesis is unknown, a genetic basis is very likely. Therefore, multiple cardiac defects should be included in the differential diagnosis of cyanosis and exercise intolerance, especially in young horses.

\section{Acknowledgements}

This paper was published in the framework of the European Social Fund, Human Resources Development Operational Programme 2007-2013, project no. POSDRU/159/ $1.5 / \mathrm{S} / 136893$.

\section{References}

Binanti, D., Zani, D. D., De Zani, D., Turci, T., Zavaglia, G. and Riccaboni, P. (2014): Contracted foal syndrome associated with multiple malformations in two foals. Anat. Histol. Embryol. 43, 71-74.

Collette, R. and Edwards, J. (1949): Persistent truncus arteriosus; a classification according to anatomic types. Surg. Clin. North Am. 29, 1245-1270.

Critchley, K. L. (1976): An interventricular septal defect, pulmonary stenosis and bicuspid pulmonary valve in a Welsh pony foal. Equine Vet. J. 8, 176-178.

Miller, M. L., Van Vleet, J. F. and Gal, A. (2012): Cardiovascular system and lymphatic vessels. In: Zachary, J. F. and McGavin, M. D. (eds) Pathologic Basis of Veterinary Disease. 5th edition. Mosby Elsevier Press, St. Louis, Missouri. pp. 539-588.

Reimer, J. M., Marr, C. M., Reef, V. B. and Saik, J. E. (1993): Aortic origin of the right pulmonary artery and patent ductus arteriosus in a pony foal with pulmonary hypertension and rightsided heart failure. Equine Vet. J. 25, 466-468.

Serres, F., Chetboul, V., Sampedrano, C. C., Gouni, V. and Pouchelon, J. L. (2009): Ante-mortem diagnosis of persistent truncus arteriosus in an 8-year-old asymptomatic dog. J. Vet. Cardiol. 11, 59-65.

Sleeper, M. M. and Palmer, J. E. (2005): Echocardiographic diagnosis of transposition of the great arteries in a neonatal foal. Vet. Radiol. Ultrasound 46, 259-262.

Steyn, P. F., Holland, P. and Hoffman, J. (1989): The angiocardiographic diagnosis of a persistent truncus arteriosus in a foal. J. S. Afr. Vet. Assoc. 60, 106-108.

Thomas, B. (2006): The Equine Heart. The Horse Report. UC Davis Center for Equine Heart 24, 4.

Van der Linde-Sipman, J. S., Goedegebuure, S. A. and Kroneman, J. (1979): Persistent right aortic arch associated with a persistent left ductus arteriosus and an interventricular septal defect in a horse. Tijdschr. Diergeneeskd. 104, 189-194.

Vitums, A. and Bayly, W. M. (1982): Pulmonary atresia with dextroposition of the aorta and ventricular septal defect in three Arabian foals. Vet. Pathol. 19, 160-168. 